\title{
LOS PROBLEMAS DE LA HACIENDA EN CATALUÑA DURANTE LA GUERRA DE LA INDEPENDENCIA
}

\author{
ANTONIO MOLINER PRADA \\ Doctor en Historia Contemporánea \\ por la Universidad Autónoma de Barcelona
}

\section{INTRODUCCION}

Durante la llamada Guerra de la Independencia, conocida en Cataluña como "guerra del francés", se produjeron en muchos pueblos motines populares. La sublevación antinapoleónica tuvo un cariz de guerra popular como antiseñorial, de revuelta social contra el Antiguo Régimen. La formación de Juntas locales y corregimentales a lo largo de todo el territorio confirma la caída de las viejas instituciones y autoridades, incapaces de hacer frente a la nueva situación. La atomización del poder en tantas Juntas constituía una seria dificultad para coordinar los esfuerzos de la guerra en momentos tan críticos. El 8 de junio de 1808 la Junta de Manresa lanzó la idea de crear un organismo superior a nivel de toda Cataluña. Sin embargo fue la de Lérida quien Ilevó a cabo tal resolución. El 9 de junio la Junta de Gobierno de esta ciudad envió una circular a tal efecto a las capitales de los distintos corregimientos. Dicha iniciativa pronto tuvo éxito. El 18 de junio se congregaron en el palacio episcopal leridano 12 de los diputados nombrados y constituyeron la Junta Superior del Principado. Como institución soberana ejerció toda su autoridad sobre las Juntas corregimentales y coordinó los esfuerzos bélicos a lo largo de todo el territorio. Su vida errante le creó innumerables dificultades pero en todo momento supo mantener encendida la llama del patriotismo. La actuación dictatorial del capitán general L. Lacy, al implantar precipitada- 
mente la Diputación Provincial de Cataluña en diciembre de 1812 , supuso el cese de la Junta que celebró su última sesión el día 1 de este mes.

Uno de los problemas básicos que tuvo que afrontar la Junta desde su constitución fue la cuestión financiera. La situación era crucial en esta guerra al estar ocupado gran parte del Principado por las tropas francesas. Según un cálculo prudencial, realizado por la junta, las rentas de Cataluña en un año normal ascendían a un total de 57.614.611 reales de vellón, desglosados del siguiente modo:

Reales vellón

Catastro territorial de todos los

Corregimientos

11.905 .830

Rentas de salinas

9.218 .781

Producto de aduanas

25.000 .000

Renta del papel sellado

1.000 .000

Noveno y Excusado

6.000 .000

Subsidio eclesiástico

90.000

Vacantes eclesiásticas

100.000

Bulas de Cruzadas y carnes

1.500 .000

Patrimonio Real

200.000

$17,5 \%$ sobre propios y arbitrios

600.000

Vacantes de la orden de San Juan ......

500.000

Renta de tabaco

1.500 .000

Total

$57.614 .611^{1}$

Básicamente lo recaudado debía de emplearse en la manutención del ejército. Si bien la Junta suprimió algunas contribuciones antiguas, las circunstancias le obligaron a introducir otras nuevas, que fueron una pesada carga para los campesinos

1 Archivo de la Corona de Aragón (A. C. A.), Sección Guerra de la Independencia (G. I.), vol. 4, f. 72 v.

Sobre la Junta Suprema de Cataluña se puede consultar mi Tesis doctoral Estructura, funcionamiento y terminología de las Juntas Supremas provinciales en la guerra contra Napoleón. Los casos de Mallorca, Cataluña, Asturias y León. Universidad Autónoma de Barcelona, Bellaterra, 1981, vol. II (Inédita). 
catalanes en una coyuntura económica recesiva y de crisis cuyo punto álgido fueron los años 1811-1812. Entre los impuestos abolidos estaban el odioso tributo personal (30 junio 1808), el del cuartillo de vino y aguardiente (6 julio 1808), el del tres y tercio de los frutos que no diezman y el de los diezmos exentos (6 julio 1808). ${ }^{2}$ En febrero de 1809 se aplicó el decreto real (20 noviembre) que abolía las tasas sobre los legados y sucesiones colaterales. En octubre de este mismo año la Junta suprimió el derecho de peajes sobre los puentes; el 28 de abril de 1810 el Congreso de Solsona abolió el derecho del $25 \%$, que cargaba sobre los diezmos percibidos por laicos, y en diciembre del mismo año el Congreso de Tarragona anuló la percepción del veinteno de todas las rentas.

La política de la Junta se basó en exigir con prontitud todos los impuestos que se cobraban anteriormente, tal como señalara en el plan de contribuciones de 26 de junio de 1808, e introdujo otros nuevos con el fin de resolver situaciones apuradas (donativos, capitación, subsidios eclesiásticos, pensiones, carnes, carrozas, diplomas, loterías, etc). No obstante la Junta de Cataluña fue incapaz de crear un sistema eficaz para recaudar los impuestos.

Para tener una idea clara sobre la situaciớn financiera del Principado a lo largo de estos años de la Guerra de la Independencia es necesario examinar la documentación de la Junta en el ramo de Hacienda que se encuentra en el Archivo de la Corona de Aragón. La obra de Desdevises sobre la Junta Superior de Cataluña sirve como punto de partida, aunque contiene afirmaciones exageradas como pensar que Cataluña contó a partir de

2 "Movidos de estas justas consideraciones la Junta Suprema Guvernativa del Reyno, que abraza ansiosamente todas las ocasiones de aliviar á los pueblos de sus cargas y recompensar abundantemente los servicios que se hacen a la Patria, a pesar de la estrechez y urgencia en que esta guerra ruinosa tiene sumido al Estado; ha determinado en nombre del Rey nuestro Señor D. Fernando VII, suprimir de una vez este género de impuestos, librando de semejante señal de esclavitud a una Provincia cuyos habitantes son todos leales, libre y valientes (...), queda abolida la contribución del personal en Cataluñan. Bando del Marqués de Coupiny publicando el Real decreto de la Junta Superior de 21 de julio aboliendo la contribución del personal en Cataluña. Tarragona, 16 agosto 1809. Biblioteca Cataluña (B. C.), Folletos Bonsoms, núm. 3892. 
1809 con un presupuesto autónomo junto al del Estado, cuando España no lo tuvo hasta 20 años después y de una manera muy precaria. $^{3}$

\section{1808: SE ESTABLECE UN PLAN DE HACIENDA}

Una de las primeras decisiones de la Junta fue adoptar un plan de contribuciones y arbitrios para formar el fondo necesario para la manutención del ejército y otros gastos. Comprendía este plan los siguientes tributos: ${ }^{4}$

a) Doble catastro. El importe doblado de la contribución que se pagaba (un $10 \%$ sobre las rentas de la tierra y un $8 \%$ sobre los productos industriales). Facultaba también a los pueblos, previa aprobación de la Junta de su corregimiento y en su caso de la Suprema del Principado, de la percepción de dicho impuesto mediante una nueva forma, la contribución de un veinteno u otra cuota general sobre los frutos de la tierra. Debía de cobrarse el primero de septiembre de 1808 , con efectos retroactivos desde el mes de mayo.

Anteriormente (20 junio 1808) la Junta había pedido un pago inmediato del 6/12 del catastro. En julio recurrió a los ricos, al cabildo eclesiástico y al gobierno inglés para que le adelantaran 150.000 duros, solicitados por Joaquín Ibáñez (Barón de Eroles). ${ }^{5}$ La Junta urgió nombrar empleados en cada Junta corregimental para poder cobrar los impuestos señalados. ${ }^{6}$ (Cervera estaba exenta de pagar el catastro hasta que en 1810 el Congreso de Solsona suprimió tal privilegio).

3 Desdevises du Dezert, G., La Junte Supérieure de Catalogne. New YorkParís, "Revue Hispanique», 1910.

El profesor Josep Fontana ha criticado estas afirmaciones en dos artículos: La financiación de la Guerra de la Independencia, "Hacienda Pública Española», Ministerio de Hacienda, Instituto de Estudios Fiscales, núm. 69, (1981), p. 212 y Qui va pagar la guerra del francès? en La Invasió Napoleònica, Bellaterra 1981, p. 12.

4 Plan de contribuciones y arbitrios para la manutención del ejército de Cataluña. Lérida, 26 junio 1808. Actas Junta Superior de Cataluña (J. S. C.), Sesión 25 junio 1808, vol. 1, fs. 45-52; B. C., Folletos Bonsoms núm. 8463.

5 Actas J. S. C., Sesión 13 julio 1808, vol. 1, fs. 149-151.

6 Actas J. S. C., Sesión 14 julio 1808, vol. 1, fs. 154-155. 
b) Salinas. Este impuesto debía de cobrarse íntegramente, tomando la cantidad de sal que tenían todos los pueblos asignada y la que necesitasen. En junio de 1808 los beneficios de las salinas de Cardona ascendían a más de 52.000 reales de vellón. ${ }^{7}$

Después, la Junta aumentó la cantidad de sal que los pueblos podian consumir. En abril de 1810 el Congreso de Solsona introdujo 12 reales por fanega de sal, provocando inmediatamente una intensificación del contrabando de este producto, hasta que en 1812 se decretó su libertad de comercio. ${ }^{8}$

c) Aduanas. Estas se continuarían cobrando con arreglo a los aranceles vigentes el 20 de mayo de 1808. La guerra y la prohibición de comerciar con Francia motivó que tales rentas disminuyeran mucho, a pesar de que el contrabando entre ambos países tanto de productos como de moneda fue muy grande. El comercio marítimo se redujo, siendo el puerto de Tarragona el más importante durante 1808-1811. La Junta permitió el comercio de vino a los corregimientos de Gerona y Mataró. ${ }^{9}$

d) Papel sellado. Se prohibió la utilización del papel sellado del gobierno intruso y se fabricó otro nuevo. Siguió aportando la misma cantidad: un millón de reales anuales. El Congreso de Solsona incrementó su precio y el de Tarragona buscó un mejor rendimiento.

e) Casas diezmeras y noveno decimal. Los subarriendos de las casas diezmeras y noveno decimal debían de permanecer como en el año 1808, no a favor de los arrendatarios generales sino a favor del fondo o caja general de la provincia.

f) Vacantes eclesiásticas. Todas las rentas de los beneficios vacantes sin excepción (arzobispos, obispos, abades, dignidades, canonjias, prebendas, beneficios, abadías, congregación benedictina claustral de Tarragona, encomiendas de la orden de San Juan de Jerusalén, etc.) pasaban a la caja provincial.

g) Fondo beneficial, subsidio eclesiástico, bulas de cruzada y carnes. Su importe se destinaría a la caja provincial. La

7 Cardona 8 julio 1808, A. C. A, G. de la I., caja 1540.

8 Desdevises, G., o. c., p, 288.

9 Desdevises, G., o. C., p, 291. 
Iglesia catalana alentó el fervor de sus fieles elevando el impuesto de las bulas de cruzada con motivo del sitio de Gerona.

h) Patrimonio Real. La Junta no reconocía las deudas pagadas al gobierno intruso antes del 18 de junio y ordenó a los propietarios (laicos o eclesiásticos) de objetos de oro y plata que entregaran una décima parte, en el plazo de un mes, a los sujetos nombrados por las Juntas corregimentales al efecto.

i) Donativos voluntarios de propietarios, comerciantes y eclesiásticos. La Junta esperaba que éstos serían cuantiosos como prueba del patriotismo catalán.

i) El $17,1 / 2 \%$ con que contribuían al Rey los propios y arbitrios de los pueblos del Principado.

k) Contribuciones sobre carnes. Un sueldo de cada libra de carne que se cobraría por el administrador respectivo semanalmente, prohibiendo su venta en las carnicerías que no estuvieran en el pueblo. (En 1810 la Junta se vio obligada a nombrar un comisario especial para activar el cobro de este impuesto). ${ }^{10}$

l) Impuesto del $5 \%$ sobre el producto de las fraguas de hierro y otros minerales. (Su resultado fue muy efímero). ${ }^{11}$

II) Bienes y rentas de la orden de San Juan de Jerusalén. Un $20 \%$ sobre las rentas netas de los encomendadores de dicha orden.

m) La capitación general. Establecida en el año 1794.

Tasas asignadas según las respectivas clases:

Pesetas mensuales

Estado noble (4 clases)...........

Comerciantes

$\begin{array}{llll}5 & 10 & 15 & 20\end{array}$

Hacendados

$\begin{array}{lll}5 & 10 & 15\end{array}$

Médicos y abogados

$\begin{array}{lll}4 & 8 & 12\end{array}$

Artistas en ejercicio

355

Procuradores y escribanos ....

Cirujanos

235

Artesanos

124

123

Jornaleros y criados

123

(2 reales de vellón)

Desdevises, G., o. c., p, 317.

11

Desdevises, G., o. c., $p, 318$. 
Estaban exentos de esta contribución los militares en ejercicio. La Junta pidió con insistencia a primeros de julio de 1808 el pago de este impuesto. ${ }^{12}$ En septiembre de 1809 su monto sumaba 28 millones de reales, estando obligados a pagar todos los ciudadanos, incluido los clérigos, aunque los obispos se manifestaron remisos a exigirlo.

n) Otros arbitrios. La Junta ordenó cesasen todas las obras públicas (puertos, canales y caminos) aplicando todos los derechos y arbitrios a la caja general de la provincia. A ella también destinarían los impuestos de los pontazgos, lezdas, pesos y medidas y los derechos y salarios exigidos por los nombramientos y títulos de bailes.

La Junta garantizaba la defensa de todas las propiedades y derechos, tanto de seglares como de eclesiásticos, en todo el territorio.

Una vez establecido el plan de contribuciones, la Junta organizó la administración de las finanzas. Estableció una caja general en Manresa y nombró a un tesorero, a un pagador general y a cuatro empleados auxiliares. Al mismo tiempo en cada corregimiento designó a un colector y a un cajero al frente de sus cajas particulares. Ninguna caja particular de los corregimientos podía sacar dinero de la caja general sin previo libramiento de ella, debiendo enviar semanal o mensualmente un estado de cuentas, así como de sus empleados, tropas y migueletes a su disposición. ${ }^{13}$ En cada corregimiento el promotor fiscal controlaría la administración de las cajas y de sus empleados, denunciando a la Junta cualquier irregularidad observada.

El 24 de septiembre la Junta acordó que los vocales señores Barata, Guinart y Torrescasana establecieran un plan sobre el acopio y distribución de víveres para la manutención del ejército. ${ }^{14}$ Dos días después creó una comisión de Hacienda con funciones de intendente, con el objeto de proponer un nuevo plan de Hacienda.

14 Actas J. S. C., Sesión 25 septiembre 1808, vol. 2, f. 28. 


\section{Otras resoluciones sobre Hacienda.}

El 24 de junio decidió la Junta que todo perceptor lego de diezmos contribuyera con un $15 \%$ del producto a la caja del corregimiento respectivo, excluyendo de tal obligación a los eclesiásticos "porque colaboraban ya con libertad". ${ }^{15} \mathrm{El} 22$ de julio determinó que las Juntas corregimentales cobrasen la capitación de todo el año y $1 / 3$ del catastro para que pudieran sostener así los gastos de los migueletes. ${ }^{16} \mathrm{~A}$ finales de junio ordenó el embargo de los bienes y derechos de las personas que fueran afectas al gobierno francés. ${ }^{17}$ En agosto impuso un derecho sobre las mercancías del $15 \%$ y también sobre los efectos y rentas de las personas residentes en Barcelona, decretando el secuestro de sus bienes el 4 de octubre. ${ }^{18} \mathrm{Al}$ cobrarse las contribuciones con mucha lentitud la Junta exhortó a los propietarios e industriales a que colaborasen con todo género de servicios. Mientras la Junta pensaba otro nuevo plan de Hacienda que conciliase la equidad y la facilidad de cobro, adoptó varios arbitrios extraordinarios: pidió donativos a eclesiásticos y a seglares; exigió 6 millones de reales en el plazo de 8 días, repartidos según catastro entre todos los corregimientos; obligó a pagar 20.000 duros en calidad de préstamos a los sujetos acaudalados del corregimiento de Tarragona y dispuso el pago de una media anualidad extraordinaria del catastro territorial a realizar en las cajas de los corregimientos; ${ }^{19}$ autorizó a la Junta de Gerona a negociar un préstamo de 100.000 duros con el gobierno inglés; ${ }^{20}$ dispuso que los propietarios del Prat de Llobregat pudiesen sacar todos sus granos para que no cayesen en manos del enemigo aun a pesar de la oposición de sus colonos, ${ }^{21}$ y ordenó a las

15 Actas J. S. C., Sesión 24 julio 1808, vol. 1, f. 221 v; vol. 15, fs. 55 v-56.

Tarragona, 9 agosto 1808. A. C. A., G. de la I. vol. 25, fs. 1-3; Id. Manifiesto de la Junta Superior de Cataluña. Tarragona, 1809, B. C. Folletos Bonsoms, núm. 1481, p. 14. (En oficio de 17 de septiembre pidió a las Juntas corregimentales le enviasen lo recaudado a la caja general, Actas J. S. C., vol. 25, fs. $30-30$ v).

20 Actas J. S. C., Sesión 11 agosto 1808, vol. 3, fs. 12 v-13.

21 Actas J. S. C., Sesión 17 septiembre 1808, vol. 4, fs. 12-12v. 
Juntas corregimentales en diciembre proceder al embargo de los granos almacenados para abastecer así al ejército. ${ }^{22}$

La Junta se vio obligada ante la escasa circulación monetaria a acuñar nuevas monedas, en las que estaban representadas las armas de la nación, el busto del Rey y la letra "C", inicial de Cataluña. ${ }^{23}$

Los donativos de la Iglesia en estos primeros meses fueron cuantiosos. En junio, el abad de Montserrat, D. Pilgneyrol, puso a disposición de las Juntas de Manresa e Igualada todos los bienes de su monasterio, a pesar de que su situación económica era deficitaria al ser bajos los arriendos y muchas las deudas sin cobrar (unas 60.000 libras), "por la tenaz resistencia de los arrendatarios en pagar sus tercias mordidas". El abad propuso a las Juntas el siguiente plan: enajenar las casas que tenía el monasterio en Manresa, Valencia, Monistrol y Olesa; la venta de terrenos incultos y la entrega de la plata. ${ }^{24}$ Por su parte, el monasterio de Poblet donó en julio la cantidad de 1.500 libras y 2.000 de oro, ofreciendo además la mitad del producto de los arriendos de todos los derechos que percibía en el corregimiento de Lérida que ingresaria en la caja general de la provincia. ${ }^{25}$ Otros donativos eclesiásticos fueron los entregados por el obispo de Solsona (43.025 reales y a partir de septiembre una renta de 2.000), por el de Tortosa (3.000 reales mensuales), por el capítulo de Lérida (128.470 reales) y el de la Seu d'Urgell (53.526 reales a título de préstamo). ${ }^{26}$ La Junta solicitó de las corporaciones eclesiásticas a partir de agosto las cantidades que pudieran aportar para remediar el déficit económico. ${ }^{27}$ El obispo de Urgell se dirigió al clero de su diócesis pidiéndoles una cuarta parte de

Actas J. S. C., Sesión 29 diciembre 1808, vol. s, f. 34.

Actas J. S. C., Sesión 13 diciembre 1808, vol. 4, f. 37 v. (Desde el 3 de julio se acuñó moneda catalana).

26 junio 1808. A. C. A., G. de la I., caja 150.

Actas J. S. C., Sesión 21 julio 1808́, vol. 1, fs. 196-197. (En octubre de 1809 el monasterio de Poblet calculaba habia entregado un total de 171.000 reales).

DESDEVISES, G., O. c., p. 299.

Actas J. S. C., Sesión 7 y 8 agosto 1808, vol. 4, f. 2 v. 
sus rentas para colaborar al sostenimiento de la guerra upor Dios, por la Religión, por la Patria y por el Rey Fernando". ${ }^{28}$

La nobleza colaboró también en los planes de la Hacienda. El conde de Alfarrás entregó 10.000 reales, el de Llupiá 20.000 y los catalanes residentes en La Habana 14.755 pesos fuertes. ${ }^{29}$

Sin embargo, a pesar de las exhortaciones de la Junta a pagar los viejos y nuevos tributos impuestos, todos los grupos sociales se resistían a aprontarlos, principalmente los campesinos. Incluso algunas Juntas, como la de Tarragona, se negaron a satisfacer los arbitrios señalados, enfrentándose directamente con la Junta Superior. ${ }^{30}$ Las quejas fueron frecuentes. El baile de Ribes de Fresser, del corregimiento de Puigcerdà, le envió un memorial señalando que debía de recurrir a las personas pudientes para sufragar los gastos del ejército, al oro y a la plata de las Iglesias y nunca a los pueblos, «aniquilados por la larga decadencia del comercio, como y de la continua exacción de pagos de los años anteriores, circunstancias que les han dexado imposibilitados a practicar lo que harían gustosos". ${ }^{31}$ Los vocales de las juntas locales de Torelló, Sluçanés, Taradell, Sant Hipòlit y Sora, presentaron a la Superior un recurso denunciando las arbitrariedades cometidas por la Junta de Vic en la distribución injusta que había hecho del préstamo forzoso. (Mientras a los individuos pobres les había solicitado grandes sumas, a los ricos sólo cantidades módicas), amenazándoles con arrestarlos si -no le entregaban las cantidades señaladas. ${ }^{32}$

La Junta reprimió los casos de insubordinación abierta contra sus decretos sobre contribuciones y recriminó con dure-

28

29

31

32

Guisona, 12 agosto 1808. A. C. A., G. de la I., caja 101.

Gracioso donativo que los catalanes residentes en La Habana hicieron de 14.755 pesos fuertes en socorro de su Patria. La Habana 24 diciembre 1808. Citado por FERRER, R., Barcelona cautiva o sea diario exacto de lo ocurrido en la misma ciudad mientras la oprimieron los franceses, esto es, desde el 13 de febrero de 1808 hasta el 28 de mayo de 1814. Barcelona, 1815, vol. 1. Apéndice núm. 15, pp. CIV-CV.

30 2, noviembre 1808 , A. C. A., G. de la I. vol. 25 , f. 68 v.

Ribas 10 julio 1808. A. C. A., G. de la l., caja 150.

27 septiembre 1808 . A. C. A., G. de la l., vol. 33 , fs. $275-276$ v. 
za a las Juntas de Balaguer y Tárrega por no haber obedecido sus dictámenes:

(...) semejante procedimiento que principalmente distingue a Balaguer y alguna otra cabeza de partido será reprimido con el mayor riesgo por la Suprema Junta que procura ahogar en su cura aquel maligno espíritu que fomentó la discordia y produce la desunión cabalmente en la misma época en que se necesita mayor intimidad y unión de voluntades. ${ }^{33}$

Exhortó a la Junta de Lérida para que pagase la media anualidad correspondiente con el objeto de estrechar más aún los vínculos de unión: "La causa que hemos emprendido no admite - afirmaba - la menor división y desunión, ni en el todo ni en sus partes. Es pues muy inconducente y fuera de propósito, que esta Junta con tales gestiones intenta pervertir el orden establecido hasta ahora y a sembrar una discordia en unos mismos pueblos". ${ }^{34}$ También abrió una investigación para averiguar la posible malversación de fondos por la Junta de Igualada. ${ }^{35}$

La crítica situación económica, debida a las malas cosechas, a la crisis comercial de años anteriores y a la presencia de tropas enemigas, motivó que algunas Juntas particulares solicitasen una disminución de sus tributos o su total exención. Según un comunicado de la Junta del Vallès la miseria e indigencia de sus habitantes era grande:

(...) pero al mismo tiempo - afirmaba - no puede prescindir de los clamores de muchos pueblos que por motivo de la falta de comercio y malas cosechas que han experimentado de algunos años a esta parte, gimen abismados en la indigencia y miseria. ${ }^{36}$

J. Padró, natural de Renau (corregimiento de Tarragona) le informaba de su triste condición a la que se veía sometido al tener que vivir de la caridad y de la limosna. ${ }^{37}$

25 septiembre 1808. A. C. A., G. de la l., vol. 25. La situación de Balaguer era comprometida, según los comisionados de su Junta existían fraudes sobre los propios y arbitrios. Balaguer, 6 diciembre 1808. A. C. A., G. de la I., caja 4.

Villafranca, 25 septiembre 1808. A. C. A., G. de la I., vol. 25, fs. $27-27$ v.

5 octubre 1808. A. C. A., G. de la I., vol. 4, fs. 20-21.

Granollers, 21 septiembre 1808, A. C. A., G. de la I., caja 2.

30 agosto 1808, A. C. A., G. de la I., caja 10. 
La maltrecha e incipiente industria textil catalana sufrió un grave revés este año al autorizar el capitán general y gobernador de Cádiz, Tomás de Merlo, con el consentimiento de la Junta sevillana, la libre entrada de tejidos ingleses de algodón por el puerto gaditano. Según su opinión Cataluña carecía de una industria algodonera:

¿Dónde están las fábricas de algodón? (...) en Cataluña, cuyo tráfico es comprar las piezas de desecho, como lo he presenciado, en las manufacturas inglesas, estamparlas con malos moldes de madera, y venderlas como géneros Nacionales, chupando así con malos y groseros géneros del numerario de las demás provincias. ${ }^{38}$

Por este motivo, los diputados catalanes en la Junta Central pidieron medidas proteccionistas para la industria naciente catalana, abocada a la ruina si se permitía la libre circulación de los tejidos ingleses, utilizando los siguientes argumentos:

Nadie ignora que en España la industria acaba de nacer, que necesita de toda la protección del Gobierno (...). Las fábricas de hilazas y tejidos están muy diseminadas y emplean a más de 150.000 almas entre hombres y mujeres y niños de ambos sexos (que se quedarían sin trabajo) (...) ¿Qué haremos de la rica y abundante cosecha de algodón de Motril y de Menorca y de nuestra América (...), entre todas las manufacturas que hay en nuestro país no hay otra que reúna más las ventajas de la industria popular que la del algodón que ocupa a las personas de todas las clases y edades de ambos sexos, que sus operaciones pueden hacerse en cualquier parte y a cualquier hora (...) que son de fácil ejecución. De ello es una prueba irrecusable el haberse extendido tanto en la población rural, en la que por este medio se ha amalgamado la agricultura y la industria con notable mejora de la primera (...). Se trata de arruinar la Provincia más industriosa de España; se trata de arruinar no sólo esta preciosa rama de nuestra industria, sino también a todos los capitalistas que se ocupan en ella. ${ }^{39}$

Su exposición finalizaba señalando que tanto Andalucía como Cataluña eran provincias de un mismo Reino, por lo que

Cádiz, 21 septiembre 1808, A. C. A., G. de la I., caja 3.

Aranjuez, 2 octubre 1808, A. C. A., G. de la I., caja 3. 
no debian de tener rivalidades mutuas, y alegaban que las reformas fiscales no correspondían llevarlas a cabo a las Juntas provinciales sino a la suprema autoridad. La Junta Central acogió favorablemente su petición y suspendió la orden dictada por el capitán general.

\section{1809: DESORGANIZACION DE LA HACIENDA}

Este año se afirmó la autoridad del Intendente del ejércto en Cataluña. La Junta creó en cada distrito una caja especial para sufragar los gastos de los somatenes. Las rentas ordinarias, valoradas en 57.614.611 reales, eran insuficientes para satisfacer los cuantiosos gastos. Pero más problemático era aún el poder cobrarlas. Tampoco dieron el resultado esperado las nuevas contribuciones impuestas por la misma razón indicada. ${ }^{40} \mathrm{La}$ desorganización de la Hacienda era total: existían muchos empleados de hospitales y finanzas sin ser necesarios, contables inexpertos, gentes que cobraban impuestos fraudulentamente, Juntas que desobedecían y protestaban por los tributos señalados y pasividad de todos los grupos sociales en pagarlos.

Las medidas introducidas por la Junta fueron antipopulares: exigir más impuestos. Intentó cobrar todas las contribuciones atrasadas ${ }^{41} \mathrm{e}$ impuso una contribución extraordinaria de 24 millones de reales a los seglares (distribuidos'en 24 clases), 7 millones a los clérigos y 481.000 a las congregaciones eclesiásticas. ${ }^{42}$ Con este nuevo impuesto, además de la capitación general, las carnes y otros, se esperaba alcanzar unos 48.001 .443 reales. Para hacer frente al sitio de Gerona el Congreso de Manresa acordó también un empréstito forzoso de 40 millones de

Por ejemplo los subarrendatarios de los derechos del noveno no los abonaban a la Junta de Talarn porque sus arrendatarios tampoco los pagaban. A. C. A., G. de la I., caja 4.

41 Circular. Poblet 16 y 31 de mayo 1809. A. C. A., G. de la I., vol. 25, fs. 220-220 v.

42 Desdevises, G., o. c., p. 266.

43 Poblet, 28 agosto 1809, A. C. A., G. de la I., caja 174. 
reales y para su amortización se pensó en imponer un veinteno sobre los frutos y rentas del Principado. ${ }^{44}$

La medida tomada por la Junta de cargar un $15 \%$ sobre las propiedades de extranjeros en el Principado fue criticada por la compañía inglesa Scott-Joles dedicada a la exportación de vinos. ${ }^{45}$ La Junta se opuso a que se restableciese el portazgo, como pretendía el Intendente de Vic, por ser éste un impuesto odioso para el pueblo. ${ }^{46}$ La Junta Central criticó también la lentitud en el cobro de las contribuciones y sobre todo la falta de claridad al no enviar las Juntas corregimentales al Intendente del ejército sus cuentas. ${ }^{47}$

Para satisfacer las necesidades del ejército la Junta siguió una política similar a la del año anterior. Ordenó el embargo de los granos almacenados y en caso de extrema necesidad el de los cosecheros y campesinos. ${ }^{48}$ Dicha medida levantó muchas protestas por lo que la Junta se comprometió a reintegrar el valor de los granos a sus arrendatarios cuando las circunstancias lo permitiesen. Estos debian de pagar lo estipulado a los propietarios de las tierras, facultándolos para rescindir sus contratos si lo hacían antes del mes de abril. ${ }^{49}$

Las Juntas locales y Ayuntamientos protestaron reiteradamente de la forma violenta como se realizaban las requisiciones y los pagos. El baile, regidores, diputados y síndicos de Terrassa se quejaron ante la Junta Superior de la cantidad que tenía que satisfacer la ciudad a la Junta de Mataró, 768 libras en tres pagos, cuando ya había entregado al ejército en concepto de vituallas más de 200.000 reales. ${ }^{50}$ Los vecinos de Valls criticaron las arbitrariedades a las que se les sometía, denunciando el hecho de que las gentes acomodadas de la ciudad estuvieran

44

45

46

47

Manresa, 29 noviembre 1809. A. C. A., G. de la I., caja 117.

15 marzo 1809. A. C. A., G. de la I., vol. 7, f. 67.

Poblet, 16 octubre 1809. A. C. A., G. de la I., vol. 17, f. 12 v.

Sevilla, 4 mayo 1809. A. C. A., G. de la I., caja 7, f. 124.

Tortosa, 4 enero 1809. A. C. A., G. de la I., vol. 25, f. 107.

Tarragona 23 marzo 1809 y 13 mayo. A. C. A., G. de la I., vol. 25, fs. 173-173 v y $199 \mathrm{v}$.

0 Poblet, 5 agosto 1809. A. C. A., G. de la I., vol. 33, f. 348. 
exentas del pago de contribuciones. La Junta no tuvo más remedio que nombrar a R. Banquells para informarse de la veracidad de los hechos denunciados. ${ }^{51}$

El intendente $J$. de Jaudenes se quejaba de la morosidad e indiferencia de las Juntas en satisfacer los pagos, mientras crecía la impotencia de las gentes. El corregimiento de Cervera, tras aportar en medio año 122.691 libras, manifestó la imposibilidad de hacer más sacrificios por ser su suelo estéril en su mayor parte y no tener comercio e industria. ${ }^{52}$ El Ayuntamiento de Rasquera presentó un recurso a la Junta de Tortosa al no poder contribuir a las raciones diarias de la tropa por la mala cosecha:

Que acudió en 2 del mismo a la Junta de Tortosa diciendo el deplorable estado, en que dicho pueblo se halla por la suma escasez de cosecha, que han reunido en este año dicho lugar y los de su comarca de todos frutos, y no sabe como dar cumplimiento a los pagos Reales y á las muchas raciones diarias á la tropa. ${ }^{53}$

Las Ilamadas de auxilio llegaron a la Junta Central. Esta se limitó a ordenar que las ayudas de otras Juntas del Principado se canalizasen a través de su Junta Superior así como cuantas peticiones le hicieran las subalternas. ${ }^{54}$

Al finalizar el año la Junta nombró a Guinart como Intendente de Cataluña y presidente de la comisión de Hacienda, formada por los señores Creus, Torrents y Barata. Con ello se daba el primer paso en la sustitución de la administración civil por la militar.

\section{1810: LOS CONGRESOS DE SOLSONA Y TARRAGONA} INTENTAN HACER FRENTE A LA DELICADA SITUACION DE LA HACIENDA

A instancias de Tomás de Veri, y con la aprobación del Consejo de Regencia, se instaló en Tarragona en marzo de 1810 un

51 Actas J. S. C., 31 agosto 1808, vol. 2, f. 65.

52 Cervera, 13 junio 1809, A. C. A., G. de la l., caja 6.

5325 junio 1809 , A. C. A., G. de la I., vol. 33 , f. 340 v.

54 Sevilla, 23 mayo 1809. A. C. A., G. de la I., vol. 7, f. 142.

55 Desdevises, G., O. c., p. 258. 
tribunal consular de comercio, presidido por el Intendente del ejército, ${ }^{56}$ con funciones similares a las realizadas por la Lonja de Mar de Barcelona para mediar en las disputas de los comerciantes. La presencia del nuevo Intendente (J. Guinart) en Tarragona se debió al objeto de defender éste los intereses del Principado frente a los deseos de la Regencia de cobrar los impuestos decretados por el gobierno central.

La delicada situación económica y financiera obligó a celebrar un congreso provincial en el mes de abril. Los viejos y nuevos impuestos percibidos eran insuficientes para satisfacer las crecientes necesidades. Estos ascendian a más de 67 millones de reales mientras el ejército necesitaba más de 10 millones mensuales. El Congreso tomó una serie de medidas para resolver la crítica situación, entre ellas el nombramiento de una comisión que buscase los recursos oportunos, como el aumento de los derechos de aduana de algunos productos (cochinilla, café, cacao, azúcar, algodón, cuero y madera) y la supresión del contrabando canalizando el comercio únicamente a través del puerto de Tarragona. ${ }^{58}$ Mientras el Consejo de Regencia aprobaba el nuevo plan enviado a tal fin, votó un préstamo forzoso de 40.000 duros. En mayo ordenó que se sustituyera la capitación acordada por la Junta Central el 12 de enero de este año por la propuesta el 28 de agosto de 1809 en Cataluña, añadiendo una nueva normativa. Una vez se establecieran las Juntas de capitación en los pueblos se convocaría a todos los vecinos en las casas consistoriales para que aplicasen con escrupulosidad el "claseo" a las respectivas fortunas. Los vecinos que no acudieran se sujetarían al pago indicado. El tanto por ciento fijado os-

Según el Consejo de Regencia las obligaciones de Intendente eran las siguientes: "La igualdad en la contribución proporcionada a las fortunas, la administración imparcial de la justicia, el fomento de la agricultura, de la cria de ganados, de la industria y de las artes, y el justo manejo e inversión de los propios, y respectivamente a la administración y recaudo de las restas y su inspección, por lo relativo al ramo de guerra, son las principales obligaciones del Intendente». Instrucción, 13 octubre 1749; 4 octubre 1799, Adicional 13 mayo 1801; 30 julio 1802, 25 marzo 1810; vol. 8, fs. 103-104, R. O. 26 mayo 1808).

14 marzo 1810. A. C. A., G. de la I., vol. 8, f. 83.

22 abril 1810. A. C. A., G. de la l., vol. 39, fs. 33-34. 
cilaba entre los que tenian que pagar 192 reales al año (16 al mes) por un capital de 116.667 reales y los que pagaban 12.000 por un capital de 1.500 .000 . A partir de esta cifra máxima por cada 250.000 reales se cargaban 2.000. Esta nueva capitación entraría en vigor a partir del 1 de julio, aunque se cobraría lo ordenado el año anterior hasta el mes de junio. El Congreso calculaba obtener así los recursos necesarios para cubrir los gastos extraordinarios. ${ }^{59}$

La Junta de Gerona solicitó del Congreso le eximiera de entregar las 1.000 cuarteras de trigo a causa del uhambre existente". ${ }^{60}$ Petición que este organismo elevó al Consejo de Regencia:

La Junta, pues, y todo el pueblo catalán concluye suplicando a V. M. al pronto envío de caudales y víveres, prestando por la última vez con la mayor solemnidad que sin estos no es posible ya el seguir con la manutención del Exto., ni el Pueblo de esta Provincia depondrá los recelos que van desgraciadamente cundiendo, de que se le abandone a la suerte, o que mira ya como a desesperada la defensa del Principado. ${ }^{61}$

En mayo, el Consejo de Tarragona se encargó de la dirección general de víveres y en el mes de julio pidió el apoyo del capitán general de Valencia para que auxiliase a las justicias y así poder cobrar los derechos del excusado y del noveno en las parroquias que pertenecientes a la diócesis de Tortosa estaban en el territorio del Reino de Valencia. ${ }^{62}$

En el mes de julio se inauguró un nuevo Congreso en Tarragona. El capitán general O’Donnell no dudó en señalar en una proclama que el punto principal a tratar en esta magna asamblea era el problema financiero:

e capitación. Solsona, 9 mayo 1810. A. C. A., G. de la l., vol. 28. fs. 289 291. En septiembre el Congreso de Tarragona aplicó la Real Cédula de 8 de julio de 1810 sobre contribuciones extraordinarias (vol. 40, fs. 139-140). En julio el Consejo de Regencia estableció una contribución extraordinaria de guerra. Cádiz 8 de julio 1810 (vol. 8, fs. 129-138).

Solsona, 26 mayo 1810, A. C. A., G. de la I., vol. 17, f. 133 v.

Tarragona, 17 julio 1810, A. C. A., G. de la I., caja 117. 
El Congreso tratará del modo de imponer las contribuciones indispensables para resistir al enemigo y mantener la fuerza armada con el menos gravamen posible de los pueblos; pero la base de esta operación será la rendición de cuentas, y la publicación de ellas por todas las autoridades, inferiores y superiores, contribuciones que han recibido, ordinarias y extraordinarias y qualquiera de las cantidades que han pagado los pueblos. ${ }^{63}$

El nuevo Congreso suprimió las pensiones que no tuviesen su aprobación, obligó a pagar los atrasos de los contribuyentes y creó un Tribunal de Cuentas con el objeto de percibir las deudas de los corregimientos remisos a abonarlas. ${ }^{64}$ Sin embargo, a pesar de las amenazas de multa, nadie quería pasar cuentas:

El Tribunal Superior de Cuenta y Razón, creado por el Congreso Provincial, recuerda en cumplimiento de su instituto á todas las Autoridades, Juntas, Gefes, Ayuntamientos e individuos que hubieran manejado caudales del público desde el principio de nuestra justa insurrección, y no han presentado cuentas algunos de ellos, la obligación estrecha que el mismo Congreso Provincial les impuso de presentarlas al Tribunal por todo el día 14 de agosto (bajo la imposiçión de multas). ${ }^{65}$

El Congreso comisionó a varios representantes para que cobrasen un préstamo a las Juntas corregimentales de dos millones de duros, ${ }^{66}$ impuso una contribución de 250.000 a los comerciantes y exigió al Consulado de Tarragona 30.000. ${ }^{67}$ Todo fue inútil, ni los empeños de la Junta, ni los del Congreso sirvieron pará conseguir el objetivo de sanear la Hacienda. ${ }^{68}$

Tarragona, 4 julio 1810. Citado por FerRer, R., vol. 6, pp. 82-83. A. C. A., G. de la I., vol. 40, fs. 22-28 y caja 178.

Sesión 20 abril 1810, A. C. A., G. de la l., vol. 39, f. 31; vol. 42, 25 julio, f. 4 v.; caja 175. 23 julio 1810, A. C. A., G. de la I., vol. 40, f. 19; vol. 42, f. 3 v. Fueron constantes las Ilamadas de las autoridades locales para que los contribuyentes pagaran los atrasos. Así por ejemplo el Gobernador militar y político de Mataró, mediante un edicto, dio un plazo de 20 dias para pagar las tercias relativas al contrato vencido, Mataró, 25 septiembre 1810. B. C., Folletos Bonsoms, núm. 8469. 
A lo largo de 1810 se exigió a cada corregimiento, en concepto de capitación las siguientes cantidades:

Tarragona

Cervera

Vic

Manresa

Puigcerdà

Talarn

Lérida

Mataró

Tortosa
192.000 duros al año (16.000 mensuales)

84.000 duros al año ( 7.000 mensuales)

72.000 duros al año ( 6.000 mensuales)

78.000 duros al año ( 6.500 mensuales)

36.000 duros al año ( 3.000 mensuales)

36.000 duros al año ( 3.000 mensuales)

108.000 duros al año ( 9.000 mensuales)

50.000 duros al año ( 4.200 mensuales)

66.000 duros al año ( 5.500 mensuales) ${ }^{69}$

La situación real, por el contrario, era muy diferente. Las cantidades aportadas por los distintos corregimientos a primeros de agosto eran las siguientes:

\begin{tabular}{|c|c|c|c|c|}
\hline \multirow[b]{2}{*}{ Tarragna } & Capitación & \multicolumn{2}{|c|}{ Préstamo } & Total \\
\hline & 32 duros & 25 & duros & 57 \\
\hline ervera. & 14 duros & 14 & duros & 28 \\
\hline Manresa ................ & 13 duros & 13,5 & duros & 26,5 \\
\hline Vic.......................... & 12 duros & 10 & duros & \\
\hline Mataró. & 10 duros & 7,5 & duros & 17,5 \\
\hline Vilafranca ........... & 10 duros & 9 & duros & \\
\hline alarn ......................... & 6 duros & 6 & duros & 12 \\
\hline Puigcerdà............ & 12 duros & 6 & duros & \\
\hline
\end{tabular}

69 A. C. A., G. de la I., vol. 175; caja 178.

7025 agosto 1810 , A. C. A., G. de la I., vol. 42 , f. 28 v. 
Para asegurar el aprovisionamiento de trigo a la tropa el Congreso ordenó un reparto entre todos los corregimientos, proporcionado a las deudas contraídas por cada uno de ellos, indicándoles el lugar donde debían depositarlo:

\begin{tabular}{|c|c|c|c|}
\hline Corregimiento & $\begin{array}{l}\text { Cuarteras } \\
\text { de Trigo }\end{array}$ & Total & $\begin{array}{l}\text { Punto de } \\
\text { destino }\end{array}$ \\
\hline 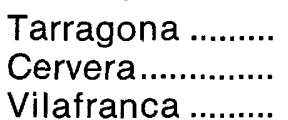 & $\begin{array}{r}11.400 \\
3.500 \\
2.900\end{array}$ & & \\
\hline 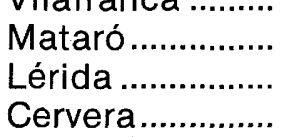 & $\begin{array}{l}1.700 \\
1.600 \\
1.000\end{array}$ & 21.000 & Tarragona \\
\hline $\begin{array}{l}\text { Barcelona .......... } \\
\text { Vilafranca ......... } \\
\text { Mataró............... } \\
\text { Manresa ............ }\end{array}$ & $\begin{array}{l}1.400 \\
2.250 \\
1.800 \\
1.7123 / 5\end{array}$ & $7.1623 / 5$ & Montserrat \\
\hline $\begin{array}{l}\text { Lérida ................. } \\
\text { Talarn ................ } \\
\text { Puigcerdà.............. }\end{array}$ & $\begin{array}{l}1.500 \\
3.000 \\
3.000\end{array}$ & 7.500 & La Seu d'Urg \\
\hline $\begin{array}{l}\text { Cervera............... } \\
\text { Manresa ............ } \\
\text { Puigcerdà........... }\end{array}$ & $\begin{array}{l}3.500 \\
1.600 \\
3.000\end{array}$ & 8.100 & Cardona \\
\hline 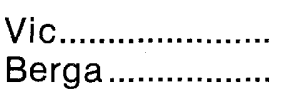 & $\begin{array}{l}5.500 \\
1.9782 / 5\end{array}$ & $7.4872 / 5$ & Berga \\
\hline & Total....... & $53.350^{71}$ & \\
\hline
\end{tabular}

Según un informe de la Comisión de Hacienda al Congreso provisional de Tarragona, el producto total de las rentas y contribuciones del Principado (desde el 1 de junio de 1809 al 31 de

71 Circular, 10 agosto 1810 , A. C. A., G. de la I., vol. 42, fs. 32 v-33. La escasez de granos empezó a ser grave en el mes de abril, nombrando una comisión para proveerse de ellos en la provincia. Sesión 24 abril 1810, vol. 39, f. 39 v. 
mayo de 1810) ascendía a un total de 48.201 .432 reales de vellón, desglosados de la siguiente forma:

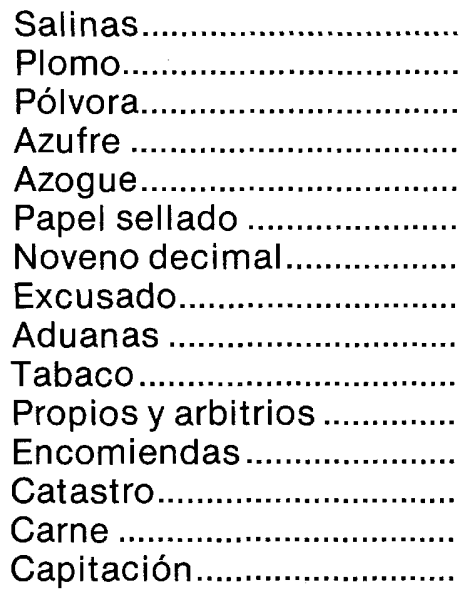

Total
6.636 .210 reales

194.313 reales

29.999 reales

46.971 reales

1.623 reales

218.418 reales

70.488 reales

40.336 reales

8.883 .816 reales

3.084 .178 reales

86.001 reales

320.000 reales

6.789 .077 reales

8.000 .000 reales

13.800 .000 reales

$48.201 .432^{72}$

La situación en 1810 llegó a ser crítica, los pueblos no tenian medios para pagar las contribuciones asignadas. A primeros de agosto la población de Valls adeudaba 6.875 duros del préstamo forzoso impuesto, Reus 6.025, Vilaseca 1.140 y Vilanova $671 .{ }^{73}$ En Sant Feliu Sasserra la cosecha no llegaba ni para cubrir las necesidades de una tercera parte del año por lo que su Ayuntamiento pidió a la Junta Superior permiso para disponer del trigo correspondiente al noveno. ${ }^{74} \mathrm{Al}$ final del año la situación era preocupante en Reus. Según un Informe de su Ayuntamiento la falta de brazos habia provocado un aumento de los salarios, el éxodo de los fabricantes había hecho disminuir la pro-

Informe Comisión de Hacienda. Agosto-Septiembre 1810, A. C. A., G. de la I., vol. 174. Otros arbitrios desconocidos según la comisión eran el producto de rentas vacantes eclesiásticas, el $15 \%$ de la amortización de los bienes adquiridos por las manos muertas, donativos, obras pías, vinculaciones, censos, etc.

A. C. A., G. de la I., vol. 179.

74 San Feliu de Sasserra, 24 agosto 1811, A. C. A., G. de Ia I., caja 178. 
ducción y el comercio y los propietarios no podían hacer frente a tantas contribuciones. ${ }^{75}$ Las protestas mediante anónimos no se hicieron esperar. Uno de ellos, fechado el 19 de diciembre, atacaba duramente al Intendente y a otras autoridades de la ciudad:

A qualsevol que entregui los ulls y ma dreta del lladre del Intendent Barata y (...) de cada Regidor, Sindichs y Taxadors de Reus lo dia 21 del corrent a la Plaza del Quartel se le pagaran 19 mil duros y farà un be á la Patria. Reus 19 desembre de 1810. Sarra, Sarra Nos lo Poble. P. D. Qui pagara sera tingut per traidor à la Patria. ${ }^{76}$

La industria lanera se vio afectada este año por el impuesto introducido (60 reales por arroba) por las Juntas de Valencia y Murcia, encareciéndola en un $50 \%$. J. Bautista Galí, en nombre de los fabricantes de la ciudad de Terrassa, exigió la mediación de la Junta-Congreso de Tarragona para que dichas Juntas permitieran la libre circulación de lana de sus territorios respectivos. Dos eran las razones aducidas: $1{ }^{a}$ por los vínculos fraternales que unían a ambos reinos con el Principado catalán y 2. ${ }^{a}$ por las nefastas consecuencias que traería la aplicación de dicho impuesto a muchas familias de Olesa, Monistrol, Esparraguera e Igualada que perderian su trabajo por el cierre de las fábricas. ${ }^{77}$ Dicha petición fue aceptada por Valencia en noviem. bre y por Murcia en octubre de este mismo año. ${ }^{78}$

\section{1811: AGRAVAMIENTO DE LA CRISIS}

Con el nombramiento de Campoverde como capitán general el estamento militar jugó un rol cada vez más importante en las finanzas. Guinart, Intendente del ejército, y Barata, Intendente de la provincia, dimitieron de sus cargos y Campoverde los reemplazó interinamente por Pío Agustín de Landa.

Reus, 30 diciembre 1810, A. C. A., G. de la I., caja 178; id. caja 175.

A. C. A., G. de la I., caja 178.

Tarragona, 18 septiembre 1810, A. C. A., G. de la I., vol. 40, fs. 145 v-146; Tarragona, 13 septiembre 1810, caja 117.

A. C. A., G. de la I., vol. 179. 
Durante este año el desorden hacendistico era total. Las Juntas se negaron reiteradamente a dar cuentas de los cobros de impuestos, desobedeciendo las llamadas del Intendente y de la Junta. El excesivo número de empleados de la Hacienda se llevaba cuantiosas sumas de lo recaudado para pagar sus salarios. El crecido número de oficiales existentes en el ejército en relación con la tropa acrecentó su déficit mensual, que ascendía a 3,5 ó 4 millones de reales. ${ }^{79}$ No sirvieron los buenos propósitos de la Junta de sanear la administración de la Hacienda, los resultados fueron muy pobres. Pensó en disminuir los sueldos de los oficiales del ejército, controlar las raciones de la tropa y reducir el número de empleados. Para salvar la situación la Junta pidió un nuevo empréstito de 9 millones de reales y recurrió a los diezmos aclesiásticos. Creó también una comisión ejecutiva de secuestros, obligó a que todos los pagos se hicieran con su visto bueno o el del Intendente y destinó a Manresa una fuerza militar para exigir el cobro de las contribuciones y verificar las quintas. ${ }^{80}$

Con el objeto de ayudar a los hospitales asignó en enero a los corregimientos las cantidades que deberían aportar: Tarragona 8.000 duros; Mataró 5.500; Vic 4.000; Manresa 4.500; Vilafranca 3.000; Talarn 2.000; Cervera 2.000; Gerona 800 y Lérida 800. ${ }^{81}$ Accedió también a las peticiones realizadas por el Ayuntamiento de Tarragona con la finalidad de fortificar la ciudad, introduciendo los siguientes impuestos: a los cafés de $1{ }^{a}$ clase 40 reales de vellón diarios, a los de segunda, fondas y mesones 20 , a las tiendas de aguas y licores 10 y a otros establecimientos 4. ${ }^{82}$

Actas J. S. C., Sesión 14 enero 1811, vol. 2 f. 98 v.

8119 enero 1811, A. C. A., G. de la I., vol, 26. fs. 23 v-24.

82 Tarragona, 29 enero 1811, A. C. A., G. de la I., vol. 26, f. 49; Actas J. S. C., Sesión 18 febrero 1811, vol. 2, f. 147. El corregimiento de Tarragona tributó en el período de junio de 1808 a fines de 1811 la cifra de 45 millones de reales. Cfr. RECASENS Comes, J. Maria, El corregimiento de Tarragona y su Junta en la Guerra de la Independencia, 1808-1811. Tarragona, 1958, p. 147. (Las pérdidas reales del sitio de Tarragona supusieron unos 100 millones de reales). 
La situación económica llegó a ser crítica. Los vecinos de Fontscaldes, jurisdicción de Valls, pidieron a la Junta les eximiese de todos los pagos por su misera situación. La Junta denegó su solicitud alegando "no permitirlo las circunstancias", 83 sin embargo accedió a que F. Alsina, campesino de Sabadell, inutilizado para el trabajo por las heridas sufridas en el combate, quedara exento de las contribuciones extraordinarias. ${ }^{84}$

El corregimiento del Vallès sufrió gran carestía de trigo y otros viveres a causa de los continuos saqueos de la tropa. Su voz llegó al Gobierno central que se limitó a ordenar al Intendente prestase la ayuda solicitada por el corregimiento. ${ }^{85}$ La Junta se opuso a las órdenes dictadas por el capitán general de Valencia que prohibían la extracción de granos de su territorio, señalando que la libertad de comercio sería beneficiosa para remediar su escasez. ${ }^{86}$

El Consejo de Regencia añadió al Reglamento provisional sobre Juntas de 18 de marzo de este año una serie de artículos referidos al Ministerio de Hacienda. Se trataba de suprimir los empleos que no fuesen necesarios, facultando a las Juntas para examinar el proceder de los empleados de la Real Hacienda, creación de una tesorería y la realización de un censo de población. ${ }^{87} \mathrm{En}$ el mes de octubre acordó también que las Juntas velasen sobre la administración del excusado y del noveno según las leyes dictadas por el Tribunal de la Cruzada. ${ }^{88}$

En el mes de agosto la nueva Junta del Principado acordó un plan que establecía un sistema económico en los suminis-

83 Tarragona, 21 enero 1811, A. C. A., G. de la I., vol. 35, f. 18.

84 Actas J. S. C., Sesión 21 enero 1811, vol. 2, fs. 11 v-112.

85 Cádiz, 6 noviembre 1811, A. C. A., G. de la l., vol. 4, fs. 358- 358 v. Días después el precio del trigo bajó 3 pesetas al llegar una remesa. Actas J. S. C., Sesión 11 noviembre 1811, vol. 2, f. 251.

86 Actas J. S. C., G. de la I. Sesión 23 abril 1811, vol. 2, f. 158 v; 24 abril 1811, vol. 25 , fs. $171-171 \mathrm{v}$.

87 Cádiz, 18 abril 1811, A. C. A., G. de la l., vol. 9, fs. 170,181 y 182 . Hasta enero de este año el Gobierno Central había aportado a Cataluña unos 44 millones de reales. Id. vol. 17. f. 273.

Cádiz, 15 octubre 1811, A. C. A., G. de la l., vol. 9, f. 324. 
tros de las tropas y en la distribución de los frutos y recursos necesarios. Las comisiones corregimentales de los pueblos cuidarían de suministrarles los víveres necesarios sólo a los que pernoctasen. Los frutos del noveno y excusado los recolectarían los cabildos eclesiásticos, cesando los colectores que había nombrado el Real Consulado, entregando su cantidad a las Juntas corregimentales. Finalmente, las comisiones corregimentales podían recoger la mitad de todos los diezmos, los frutos pertenecientes al gran Priorato de Cataluña y demás encomiendas vacantes de la orden de San Juan de Jerusalén. ${ }^{89}$

La escasez de viveres para la tropa obligó a que la Junta acordara en el mes de octubre el siguiente reparto entre los distintos corregimientos:

Vic: 4.000 cuarteras de maíz, 150 de judías, 40 bueyes y 174 carneros.

Mataró: 100 cuarteras de judías.

Cervera: 50 cuarteras de judías y 2.952 arrobas de aguardiente.

Talarn: 50 cuarteras de judías, 126 bueyes y 530 carneros.

Lérida: 100 cuarteras de judías.

Tarragona: 50 cuarteras de judias.

Vilafranca: 50 cuarteras de judias y 800 arrobas de aguardiente.

Barcelona: 50 arrobas de aguardiente.

Manresa: 50 cuarteras de judias y 1.909 arrobas de aguardiente.

Figueres: 1.000 cuarteras de maíz, 50 de judías, 44 bueyes y 256 carneros.

Puigcerdà: 487 cuarteras de avena, 50 de judias, 39 bueyes y 130 carneros. $^{90}$

89 Plan de suministros tropa. 1 agosto 1811, A. C. A., G. de la I., vol. 26 fs. 394 y ss.

90 Berga, 25 octubre 1811, A. C. A., G. de la I., vol. 26, fs. 576 v-577. 


\section{1812: HAMBRE Y MISERIA}

Ante las crecientes dificultades para percibir los impuestos la Junta pidió al Intendente interino Andrés Ibáñez un plan de reorganización de las finanzas. Su objetivo prioritario era recaudar las rentas con prontitud, proporción y equidad, para remediar las necesidades del ejército, y cortar los desórdenes introducidos en la Hacienda por la codicia y mala fe de algunos acreedores o por la insubordinación de cuantos manejaban caudales públicos. El plan, presentado en Vic el 17 de diciembre de 1811, fue aprobado por el capitán general y por la Junta el 6 de febrero de 1812. Se establecieron comisarios de guerra con el carácter de Ministros de la Real Hacienda, representando al Intendente en cada cantón, para activar el cobro de las contribuciones ordinarias y extraordinarias, procurar la asistencia a la tropa, ciudar de su socorro en los casos urgentes, evitar la percepción de ayudas dobles, dar razón de los caudales existentes en cada cantón, instar a las comisiones populares a que presentasen sus cuentas y ser intermediarios entre el Intendente, administradores y contribuyentes.

Se dividió el Principado en 7 cantones (Vic, Mataró, Manresa, Vilafranca, Cervera, Talarn y Puircerdà), en cada uno de los cuales residiria un comisario con los fines señalados. Una de su primera misión sería el cerciorarse a través de las autoridades del estado de las contribuciones ordinarias y extraordinarias exigidas, informando de ello al Intendente. A su cargo estaba el cobro de todas las contribuciones, pudiendo utilizar la fuerza armada para conseguir que pagasen las deudas atrasadas contraídas con la Hacienda. También tenían la función de subinspectores de provisiones de víveres, controlando sus entradas y salidas y autorizando los recibos de suministro. Velarían en todo momento para que las comisiones corregimentales cobrasen con puntualidad los préstamos y contribuciones extraordinarias, publicando cada diez días las cantidades percibidas e informando de ello al Intendente. Mensualmente señalarían las cantidades entregadas a particulares o a otros cuerpos, auxiliando en todo momento a las comisiones populares y Ayuntamientos para el arreglo de recibos y formación de cuentas. Fi- 
nalmente, debian de pasar revista a la tropa los días primero y decimosexto de cada mes, informando del estado de la fuerza. ${ }^{91}$

Sin embargo, la aplicación de este nuevo plan solucionó muy pocas cosas, más aún, ocasionó continuos roces entre la Junta y el Intendente. El saneamiento de la Hacienda fue imposible conseguirlo en un año tan crítico como el de 1812. A finales de enero la Junta se dirigió a los diputados catalanes en las Cortes solicitando ayuda para remediar el hambre:

Todo, todo, Srs. Diputados - decía- presenta en Cataluña el aspecto más lúgubre; y lo que es más sensible, la hambre va a sellar mui en breve el heroismo. ${ }^{92}$

En febrero, la Junta elaboró un plan para procurar los víveres necesarios. Para solucionar la carestía de cereales pensaba reunir un fondo de 50 o 60 mil duros mensuales para su compra, facilitando su entrada en los puertos de mar sin ningún recargo y embargando los buques que llevasen este cargamento. ${ }^{93}$ En el mes de abril nombró una comisión para establecer una tributación fija, estable y justa, que no se hiciera odiosa al pueblo, ${ }^{94}$ aunque no se llevó a la práctica después de que presentara en septiembre el informe respectivo. Exigió la mitad de todos los diezmos eclesiásticos y legos de las cosechas. A tal efecto las Juntas corregimentales nombrarían a un comisionado que establecería su valor de común acuerdo con el perceptor o colector de los diezmos, auxiliado por las justicias que castigarían cuantos abusos y fraudes se cometieran. ${ }^{95}$ Acordó también una nueva normativa para el cobro de la casa mayor diezmera y noveno decimal, ${ }^{96}$ valorando su cuantía en pública subasta ${ }^{97}$ y solicitó

Vic, 17 diciembre 1811, A. C. A., G. de la I., vol. 29, fs. 76-77; caja 146.

Berga, 28 enero 1812, A. C. A., G. de la I., vol. 19, f. 24.

Circular de la Junta Suprema de observación y defensa del Principado de Cataluña. Berga, 19 febrero 1812, A. C. A., G. de la I., vol. 29; B. C. Folletos Bonsoms, núm. 8481.

Berga, 16 abril 1812, A. C. A., G. de la I., vol. 29, fs. 207-207 v.

Berga, 15 mayo 1812, Reglamento de la Junta Superior del Principado para cobrar una contribución extraordinaria de la mitad de todos los diezmos, A. C. A., G. de la I., vol. 29, fs. $269-272$ v; Id. B. C.; Folletos Bonsoms núm. 8489.

Berga, 19 mayo 1812, A. C. A., G. de la I., vol. 29, fs. 271-272. 
del Gobierno la vigencia del acuerdo sobre exención de impuestos a los granos y víveres que llegaran al Principado, anulado en el mes de abril. ${ }^{98}$

Para remediar la escasez de granos, la Junta elaboró un plan de recaudación de trigo, distribuido equitativamente entre todos los corregimientos y pueblos, cuyas cantidades debían de entregar en el punto señalado antes del 15 de agosto. Estas fueron las cuarteras señaladas a cada corregimiento:

\begin{tabular}{|c|c|c|}
\hline Corregimiento & Cuarteras & Punto de destino \\
\hline $\begin{array}{l}\text { Tarragona .......... } \\
\text { Lérida ................. } \\
\text { Cervera ............... }\end{array}$ & $\begin{array}{r}1.184 \\
752 \\
581\end{array}$ & $\begin{array}{c}\text { Vilanova } \\
\text { La Seu d'Urgell } \\
\text { La Seu d'Urgell y } \\
\text { Cardona }\end{array}$ \\
\hline Manresa ... & 346 & Cardona \\
\hline Vic............... & 493 & Cardona \\
\hline Mataró .................. & 576 & Montserrat \\
\hline Vilafranca & 518 & Montserrat \\
\hline Talarn .................. & 214 & La Seu d’Urgell \\
\hline Puigcerdà........... & 213 & La Seu d’Urgell \\
\hline Barcelona .......... & 400 & Cardona \\
\hline Gerona ............. & 1.350 & $\begin{array}{l}\text { a disposición del } \\
\text { brigadier Rovira }\end{array}$ \\
\hline Figueres............. & 640 & $\begin{array}{l}\text { a disposición del } \\
\text { brigadier Rovira }\end{array}$ \\
\hline Total & $7.7170^{100}$ & \\
\hline
\end{tabular}

En el mes de agosto impuso una contribución extraordinaria para socorrer al ejército, distribuida entre todos los corregimientos del siguiente modo:

Sallent, 25 junio 1812, A. C. A., G. de la I., vol. 29, fs. 341-341 v.

Sallent, 9 julio 1812, A. C. A., G. de la I., vol. 29, fs. $368-369$ v. El Ayuntamiento de Manresa pidió se suprimiesen todas las trabas que obstaculizaban la libre circulación de granos y viveres.

99 Reglamento recaudación de trigo, A. C. A., G. de la I., vol. 29, f. 404; B. C., Folletos Bonsoms, núm. 4067.

100 Noticias de las quarteras de trigo que deven señalarse a cada corregimiento y repartirse entre los Pueblos del mismo y puntos de depósito donde deben conducirse. Sallent, 24 julio 1812, A. C. A., G. de la l.; vol. 29, f. 398. 
Duros

\begin{tabular}{|c|c|}
\hline Tarragona. & 70.500 \\
\hline Lérida ........... & 8.000 \\
\hline Figueres ......................... & 7.500 \\
\hline Vilafranca.... & 22.500 \\
\hline Cervera....... & 31.600 \\
\hline Puigcerdà...... & 7.500 \\
\hline 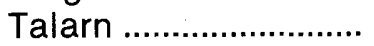 & 16.500 \\
\hline 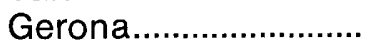 & 29.000 \\
\hline Barcelona..................... & 67.500 \\
\hline Mataró ........................... & 20.000 \\
\hline 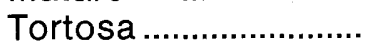 & 30.000 \\
\hline 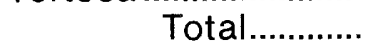 & $389.500^{101}$ \\
\hline
\end{tabular}

La Junta preveía obtener con la contribución extraordinaria y la tercera parte de los arriendos de los medios diezmos, excusado y noveno un total de 10.100 .000 reales, desglosados de la siguiente forma:

Tercia sencilla de catastro

1.500 .000 reales

Contribuciones sobre pueblos

6.000 .000 reales

Contribuciones sobre pueblos 600.000 reales

Medio diezmo, excusado y noveno hasta el mes de septiembre

2.000 .000 reales ${ }^{102}$

En su opinión la situación caótica de la Hacienda se debía principalmente a la inseguridad reinante en todo el territorio, al extravío de papeles y a los continuos cambios en su administración:

Puesto el gobierno de Cataluña, como el de las demás provincias, en tantas manos divididas, en tantos trozos quantos son los partidos de que consta, la variación de gobernantes quasi continua o a lo menos muy frecuente y la inseguridad general del Principado con las fugas, emigraciones, extravíos o pérdida de papeles y otras causas, tal es el origen funesto del caos en que se halla el ramo de contribuciones y de la hacienda pública en Cataluña. ${ }^{103}$

101 Sallent, 4 agosto 1812, A. C. A., G. de la I., vol. 29 , f. 420 v.

102 A. C. A., G. de la I., vol. 29, f. 429.

103 Sallent, 10 septiembre 1812, A. C. A., G. de la I., vol. 19, f. 303 v. 
En septiembre la Junta se dirigió al Consejo de Regencia pidiéndole con urgencia medidas drásticas para evitar el hambre en todo el Principado, debido a su parecer a la mala cosecha del año anterior y a la sequía del verano en curso. ${ }^{104}$

Los proyectos de la Junta a lo largo del año no se cumplieron, sobre todo la requisición de granos ordenada. ${ }^{104} \mathrm{~A}$ finales de noviembre trazó un balance de lo recaudado en concepto de arriendos de medios diezmos, noveno decimal, casas mayores diezmeras y contribución extraordinarias: de los 10.704.374 reales previstos sólo habia obtenido una tercera parte de ellos, 3.611.518. Esta era la cruda realidad:

\begin{tabular}{|c|c|c|}
\hline Corregimiento & $\begin{array}{c}\text { Cantidad } \\
\text { entregada (reales) }\end{array}$ & $\begin{array}{c}\text { Cantidad } \\
\text { adeudada (reales) }\end{array}$ \\
\hline Barcelona ........... & 514.125 & 892.064 \\
\hline Cervera.................... & 552.786 & 679.407 \\
\hline Figueres.............. & 3.664 & 147.596 \\
\hline Gerona .................... & 31.260 & 553.613 \\
\hline Lérida ......................... & 94.814 & 170.304 \\
\hline Manresa .............. & 247.825 & 767.020 \\
\hline Mataró..................... & 217.025 & 443.215 \\
\hline Puigcerdà........... & - & 395.643 \\
\hline Tarragona ........... & 823.355 & 794.402 \\
\hline Talarn ....................... & 311.777 & 341.299 \\
\hline Tortosa.................. & $\cdots$ & 605.042 \\
\hline Vic........................... & 262.185 & 1.069 .633 \\
\hline Vilafranca ........... & 544.299 & 243.612 \\
\hline Total ....... & 3.611 .518 & $7.092 .856 \quad 106$ \\
\hline
\end{tabular}

104 Oficio a la Regencia. Vich, 30 septiembre 1812, A. C. A., G. de la I., vol. 19, fs. 346-347.

105 Vich, 14 octubre 1812, A. C. A., G. de la I., caja 23.

106 Noticia de las cantidades que deben aprontar las comisiones corregimentales por razón de la tercera parte vencida en 1 de septiembre último, de los arriendos de medios diezmos, R. Noveno decimal y casas mayores dezmeras, y del cupo de contribuciones extraordinarias pertenecientes a cada una de las mismas, con expresión de las partidas entradas en tesorería y entregadas a la dirección de suministros y de lo que adeudan en el día de la fecha. Berga, 26 noviembre 1812. vol. 29, f. 616. 
A lo largo de este año fueron muy frecuentes las protestas de los pueblos. El Ayuntamiento de Sabadell se quejó a la Junta porque la corregimental de Mataró le impuso la cantidad de 2.000 duros como contribución, además de otros 2.000 en concepto de atrasos. Al entregar el baile de la ciudad solamente la primera cantidad fue arrestado, debiendo pagar todo lo asignado para poder obtener su libertad. ${ }^{107}$ El baile y otras autoridades de Castellar del Vallès solicitaron eximiera al pueblo de las contribuciones en honor a su "patriotismo". Medida que no aceptó la Junta aunque accedió a rebajarle el pago de un mes. ${ }^{108} \mathrm{EI}$ Ayuntamiento de Vilanova, que desde septiembre de 1811 a marzo de 1812 había contribuido con la cantidad de 108.902 reales, se vio obligado a establecer una suscripción popular para poder dar de comer a las familias expatriadas Ilegadas a la ciudad. ${ }^{109}$ La ciudad de Manresa, tras ser saqueada por quinta vez en el mes de noviembre, se dirigió a la Junta trazándole un plan muy sombrío:

(...) con tantos estragos y tantas pérdidas el comerciante ha quedado abatido, el artesano sin medios para ganar su preciso sustento y todos en general reducidos a una extrema miseria. ${ }^{110}$

Una vez más la protesta popular se manifestó mediante los anónimos. Uno de ellos decía así: "(...) los padres de la Patria son sus mayores enemigos. Ellos exigen todos los sacrificios, pero ¿para qué? Para fomentar la más negra trayción (...) Sois ladrones públicos". ${ }^{111}$

\section{CONCLUSION}

La Guerra de la Independencia supuso para la economía catalana un duro revés. Las transformaciones económicas de la segunda mitad del siglo XVIII, que habían supuesto un cambio

10720 enero 1812, A. C. A., G. de la I., vol. 36, fs. 11-12.

108 Berga, 4 abril 1812 , A. C. A., G. de la I., vol. 36 , fs. $80-80$ v.

10931 marzo 1812, A. C. A., G. de la I., caja 20; 21 mayo 1812, vol. 36, f. 75.

110 Oficio del Ayuntamiento a la Junta Superior. Manresa 22 noviembre 1812. A. C. A., caja 21.

111 A. C. A., G. de la I., caja 19. 
en el principio del modo de producción, se vieron truncadas por los efectos negativos de la guerra: destrucción de las cosechas, ganados y propiedades, acaparamiento de los productos de primera necesidad y aumento de la presión fiscal en los pueblos.

Las Juntas locales y los guerrilleros se incautaron sucesivamente de los productos de los campesinos y en ocasiones éstos se vieron sometidos a la fiscalidad francesa cuando sus territorios caían en su manos. La comisión de Hacienda, creada en el interior de la Junta, intentó desde el principio reunir los fondos necesarios para sufragar los cuantiosos gastos existentes, obligando a todos los pueblos y grupos sociales a prestar su colaboración. Sin embargo, como hemos podido comprobar, fue incapaz a lo largo de estos años de llevar a cabo con eficacia un plan de Hacienda, sus proyectos fueron más teóricos que reales. La excesiva presión fiscal a la que se sometió a los pueblos provocó una cierta pasividad en pagar los impuestos y al mismo tiempo su repulsa contra los excesos cometidos por los soldados y migueletes en las cosechas y propiedades de los campesinos.

Como ha señalado el profesor Josep Fontana la financiación de esta guerra no se hizo básicamente ni desde el Gobierno Central (Junta Central, Consejo de Regencia y Cortes) ni desde las Juntas Superiores, más bien los gastos de la defensa se organizaron a partir de las iniciativas locales y de la fiscalización inmediata, como se comprueba en el caso de Cataluña. ${ }^{112} \mathrm{El}$ dinero se sacaba de donde se podía. Los guerrilleros y Juntas locales pedían a los pueblos los impuestos necesarios para subsistir en forma de préstamo forzoso. En ciudades y pueblos se constituyeron Juntas de recursos para hacer frente a las necesidades más perentorias.

Una vez más, los gastos recayeron principalmente sobre los campesinos y sobre la pequeña industria rural tan ligada a la agricultura. La burguesía catalana, casi en su totalidad, se refugió en Mallorca llevándose consigo gran parte de sus riquezas. Lógicamente durante estos años afloraron actitudes hostiles que atacaban las mismas bases del sistema social. Muchos 
campesinos aprovecharon la coyuntura de la guerra para no pagar los derechos y prestaciones señoriales. Los ejemplos son muy frecuentes: los vecinos de Falset contestaron a los recaudadores de impuestos que por no tener rey no debian de pagar; los pobres de Cunit manifestaron a su Ayuntamiento que pagasen los ricos; en Martorell proclamaron la igualdad, etc. ${ }^{113} \mathrm{La}$ protesta del campo se alzaría después a lo largo del siglo XIX en las zonas más empobrecidas por esta contienda. En definitiva la segunda etapa de la revolución industrial en Cataluña se construiría sobre la ruina del campo y no sobre su esplendor como en la primera etapa.

Evaluar los costos de esta guerra en Cataluña es un objetivo actualmente difícil de calcular. La tesorería general señalaba en febrero de 1814 la cantidad de 488.224 .657 reales gastados por el ejército en los cinco primeros años. A esta cifra se debería añadir los 40.000 millones aportados para romper el sitio de Gerona y unos 500.000 en razón de alimentos. En total más de 1.000 millones de reales, como ya señalara hace años Desdevises. ${ }^{114}$ No obstante se hace necesario tener en cuenta también otras cantidades de dinero entregadas a ambos bandos, la fiscalización inmediata de los pueblos, sin contabilizar todavía, y el valor de las casas, cosechas y ganados destruidos, y de los robos efectuados, además del número de muertos. Por todo ello se hace imprescindible realizar estudios locales con este objetivo.

113 A. C. A., G. de la I., vol. 17; Id. caja 151.

114 Desdevises, G., o. c., p, 279. 